\title{
Variation of traffic flow due to accumulated snow formation on road
}

\author{
Kazunori Munehiro ${ }^{1, *}$, Naohisa Nakamura $^{1}$, and Masaya Sato $^{1}$ \\ ${ }^{1}$ Civil Engineering Research Institute for Cold Region, Hiragishi 1-3-1-34, Toyohira-ku, Sapporo, \\ 062-8602, Japan
}

\begin{abstract}
Sapporo City has one of the heaviest snowfalls worldwide, and the road conditions in winter are getting remarkably worse. Snow removal works in winter are indispensable in order to secure traffic functions in the city. Snow accumulates on roads as soon as it is removed. It is also a problem that the deposited snow protrudes into the lanes of roads and the traffic flow drops. This study analyzed the size of deposited snow formation and the variation of traffic flow. We set up a camera for a four-lane road managed by Sapporo City (two lanes per side) and observed two seasons continuously. Width of deposited snow and traffic performance (Traffic Volume - Velocity) were analyzed based on the acquired images. The width of deposited snow was from $1.0 \mathrm{~m}$ to $2.5 \mathrm{~m}$. When the width of the deposited snow exceeded approx.1.5 m, it was indicated that only one lane of the road will be in operation if it is originally operated as two lanes per side, with about $70 \%$ of the traffic volume and about $80 \%$ of the speed. In addition, based on the actual situation of use of bicycles and pedestrians in autumn, we propose redistribution of road cross-sections considering snow coverage width.
\end{abstract}

\section{Introduction}

On roads in snowy areas, the treatment of snow on the roads is important. There is falling snow, piled snow and snow accumulated on the roadway, the shoulder and the sidewalk due to snow removal. Snow on the road deteriorates traffic performance. In some cases, it can cause massive traffic hazards.

The city of Sapporo, Japan, is located at 43 degrees north latitude and 141 degrees east longitude. The day high temperature in January and February in midwinter is minus 1 degree in a normal day value and the day minimum temperature in a normal day value is minus 7 degrees. The annual cumulative snowfall amount reaches about $6 \mathrm{~m} \mathrm{[1].} \mathrm{The} \mathrm{population} \mathrm{of}$ Sapporo City is about 1.9 million people. The city has one of the heaviest snowfalls worldwide, and the road conditions in winter are getting remarkably worse.

In snowy areas like Sapporo City, snow removal work by machines is generally carried out in order to secure road traffic during snowfall. "Snow removal works" to eliminate snow covering the roadside and "Snow removal widening works" to secure width for traffic in winter time are carried out. In the commentary and operation of Japan's Road Structure Order,

\footnotetext{
*Corresponding author: k-munehiro@ ceri.go.jp
} 
it is stated, "The width of the central zone, road shoulder and bicycle pedestrian street or sidewalk in the snowy area depends on the topography, land use situation, snow removal and snow melting method, in consideration of snow accumulation width to ensure snow coverage width."[2-4] In snowy areas, it is important to secure a space where removed snow can accumulate, that is, for the width of deposited snow. [5] However, there are cases in which the effective road width decreases with the formation of accumulated snow, and road traffic performance in winter decreases. But such reported cases are few. [6]

The purpose of this research is to report the actual measurement results of winter road traffic performance by the formation of accumulated snow for roads in Sapporo City. We also propose redistribution of road space in consideration of the actual utilization of a crosssection configuration in autumn and winter.

\section{Study method}

\subsection{Outline of experiments}

The target road is a four-lane road managed by Sapporo City. The cross-sectional configuration consists of a roadway part $(3.0 \mathrm{~m} /$ lane $)$, a shoulder part $(0.5 \mathrm{~m})$, and a sidewalk part $(3.5 \mathrm{~m})$. The observation camera was installed on an F-type sign on the roadside. Continuous observations were made on the formation of sediment and the traffic flow in winter. Observation went through two winter seasons. Images of the observation camera were continuously acquired. Using image analysis software, data on sediment formation and traffic flow were obtained and tabulated.

In the current operation, it is required to secure $2.0 \mathrm{~m}$ as the snow accumulation space (primary snow width) of the target road. The observation target road is shown in Fig. 1, and the summary of winter data acquisition is shown in Fig. 2.

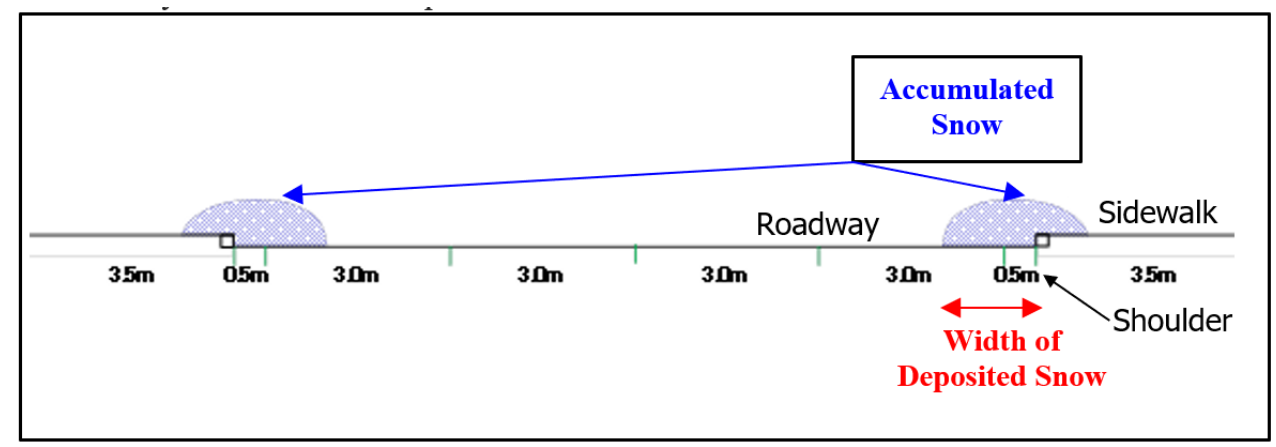

Fig. 1. Cross-sectional configuration of target road. 


\begin{tabular}{|c|l|}
\hline Route Name & Prefectural Road Route 452 Shimoteine-Sapporo Line \\
\hline Location & Hassamu 14-jo 11-chome, Nishi-ku, Sapporo City \\
\hline $\begin{array}{c}\text { Road Cross } \\
\text { Section }\end{array}$ & $3.5-0.5-3.0 @ 4$ lane $-0.5-3.5(\mathrm{~m})$ \\
\hline $\begin{array}{c}\text { Observation } \\
\text { Period }\end{array}$ & From Dec.2016 to Feb.2017 \\
\hline & From Dec.2017 to Feb.2018 \\
$\begin{array}{c}\text { Aggregated } \\
\text { Data }\end{array}$ & $\begin{array}{l}\text { 2) Roadth of Deposited Snow (m) } \\
\text { 3) Traveling Position in Transverse Direction } \\
\text { 4) Traffic Volume (vehicles } / 5 \text { min.) } \\
\text { 5) Velocity (km/h) } \\
\text { 6) Gap (sec) }\end{array}$ \\
\hline
\end{tabular}

Fig. 2. Outline of winter data acquisition.

\subsection{Summary data item}

Images acquired during the winter season were analyzed for 120 hours. Data was organized as follows.

\subsubsection{Width of Deposited Snow}

In this paper, we sort out the width of snow deposits from the curbs of the sidewalk to the roadway every 0.5 meters. The autumn term is based on images acquired in November 2016 for comparison with the winter season.

-Autumn (Dry) : 0 m,

$\cdot$ Winter (Snow) : 0m, 0.5m, 1.0m, $1.5 \mathrm{~m}, 2.0 \mathrm{~m}, 2.5 \mathrm{~m}$

\subsubsection{Road Surface Conditions}

The road surface conditions were divided into the following five categories:

- Dry, wet, fresh snow, compacted snow, frozen

\subsubsection{Vehicle Traveling Position of Transverse Direction}

For the crossing direction of the lane, it was divided at intervals of $1 \mathrm{~m}$. It was judged by the passage position of the license plate located at the center of the vehicle. It was divided into two lanes as follows in Fig.2:

1. Inner lane: No.1, No.2, No.3

2. 2. Outer lane: No.4, No.5, No.6

\subsubsection{Other acquired data in winter}

The data acquired in winter are as follows:

-Traffic Volume (Vehicles/5min.)

-Velocity of Vehicle $(\mathrm{km} / \mathrm{h})$

- Gap (sec) 


\subsubsection{Other acquired data in autumn}

The data acquired in the autumn dry road conditions are as follows:

-Traveling Position: Roadway, Shoulder, Sidewalk

-Bicycles

-Pedestrians

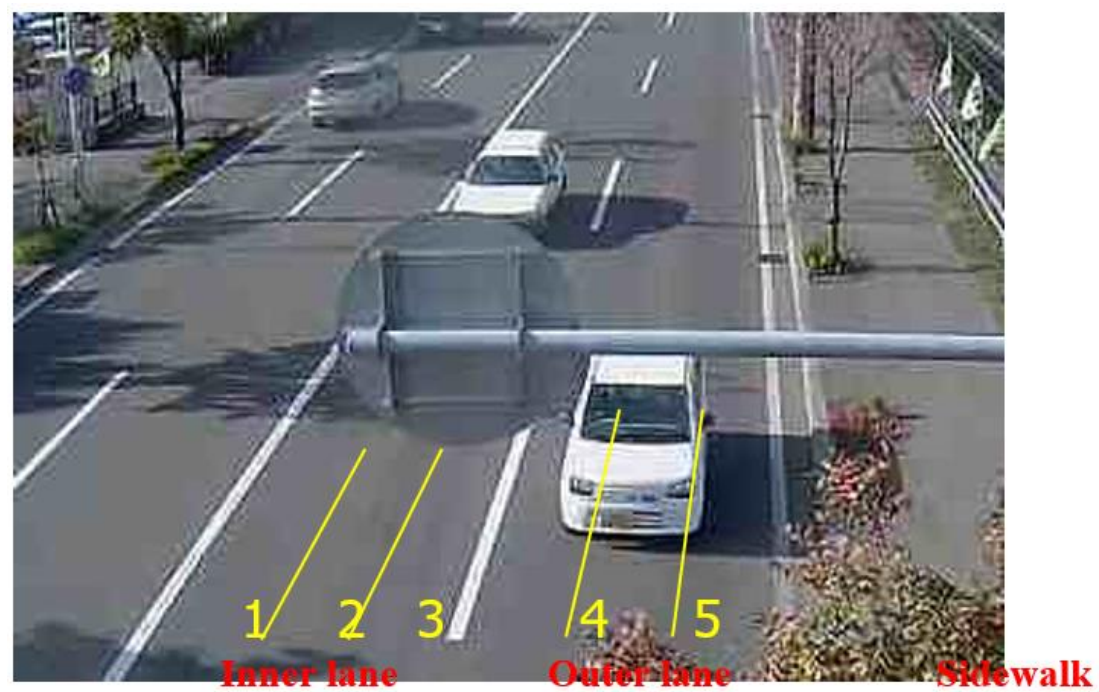

Shoulder

Fig. 3. Vehicle Traveling Position of Transverse Direction.

\subsubsection{Other acquired data in winter}

The data acquired in winter are as follows:

-Traffic Volume (Vehicles/5min.)

-Velocity of Vehicle $(\mathrm{km} / \mathrm{h})$

-Gap (sec)

\subsubsection{Other acquired data in autumn}

The data acquired in the autumn dry road conditions are as follows:

-Traveling Position: Roadway, Shoulder, Sidewalk

-Bicycles

-Pedestrians

\section{Study results}

\subsection{Measurement result of traffic flow in winter}

\subsubsection{Velocity distribution by width of deposited snow}

We compiled the images observed during the two winter seasons. The speed distribution of the vehicle was organized according to the width of the deposited snow, and Figure 4 was 
obtained. The width of the deposited snow was with 0.0 to $2.5 \mathrm{~m}$ of targeted fresh snow or compacted snow on the road surface. Regarding $0.0 \mathrm{~m}$ (dry), it covered the dry road surface in autumn. As the width of the deposited snow increased, the velocity of the vehicle tended to decrease.

With a width of $1.5 \mathrm{~m}$, the average value is about $35 \mathrm{~km} / \mathrm{h}$ and the 85 th percentile value is about $45 \mathrm{~km} / \mathrm{h}$. However, when the width of deposited snow reached $2.0 \mathrm{~m}$, the average value decreased to about $27 \mathrm{~km} / \mathrm{h}$ and the 85 th percentile value was about $36 \mathrm{~km} / \mathrm{h}$.

With a width of $1.5 \mathrm{~m}$ of snow cover, $5.0 \mathrm{~m}$ is secured as the width for securing winter traffic in two lanes on one side. However, with a width of snow cover of $2.0 \mathrm{~m}$, the winter traffic securing width in two lanes on one side is reduced to $4.5 \mathrm{~m}$. It is considered that this is actually a condition of one lane operation on one side. Examples of acquiring images when the width of deposited snow is $1.5 \mathrm{~m}$ and the width of deposited snow $2.5 \mathrm{~m}$ are respectively shown in Figure 5.

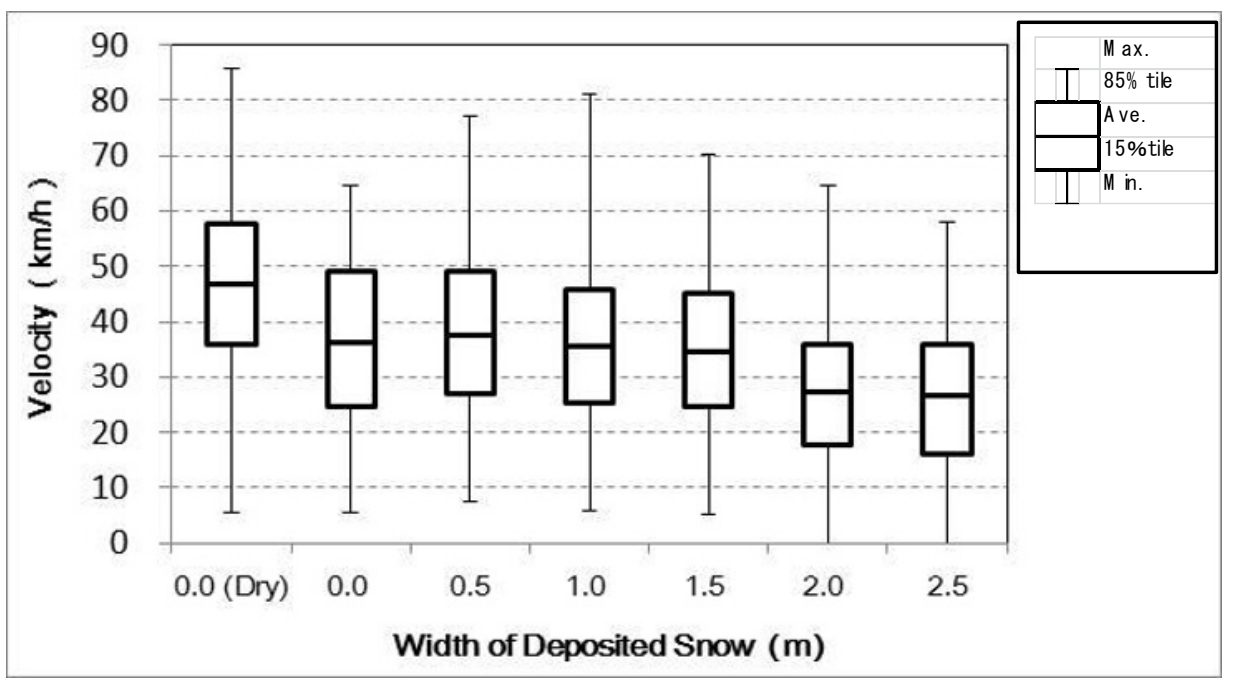

Fig. 4. Velocity distribution by width of deposited snow.

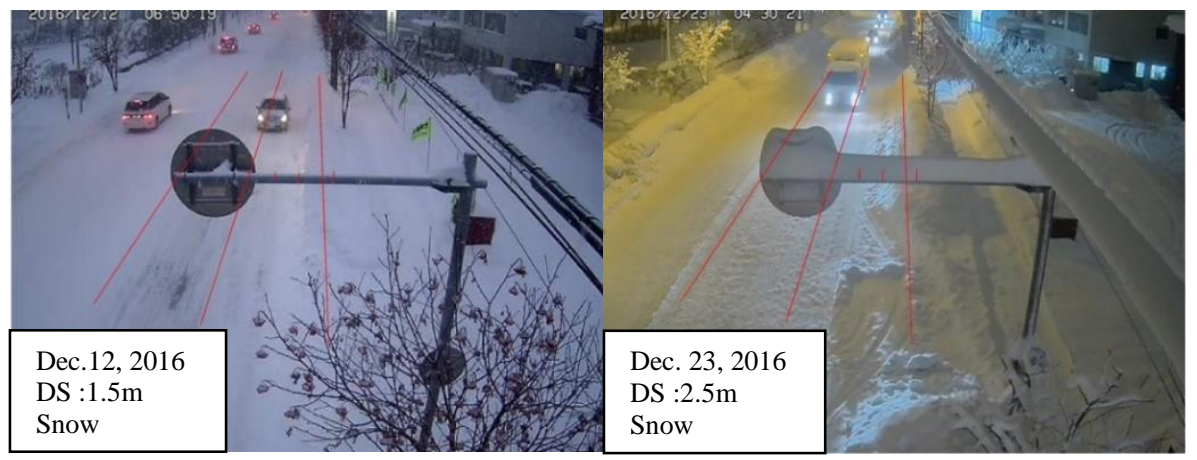

Fig. 5. Examples of acquiring images (Left: Width of Deposited Snow is $1.5 \mathrm{~m}$, Right: Width of Deposited Snow is $2.5 \mathrm{~m})$.

\subsubsection{Vehicle traveling position by width of deposited snow}

Data on vehicle traveling position was acquired for each width of deposited snow, and Fig. 6 was obtained. Of the two lanes on one side, No.1, No.2 and No.3 show the inner lane 
running, and No.4, No.5 and No.6 show the outer lane traveling. As the width of the deposited snow increased from 0.0 to $2.5 \mathrm{~m}$, the ratio of No.3 and No.4 to the driving position increased.

On the other hand, the proportion of using No.1 $\cdot$ No. 2 and No.5 $\cdot$ No.6 as running position decreased greatly. The total of No.3 and No.4 reaches $58 \%$ when the snow covers $1.5 \mathrm{~m}$ in width, $75 \%$ when the snow deposited width is $2.0 \mathrm{~m}$, and $84 \%$ when the snow coverage width is $2.5 \mathrm{~m}$. Therefore, there was a tendency that the operation of one lane on one side increased from $1.5 \mathrm{~m}$ in width of snow. About $80 \%$ of the vehicles traveling were found in the middle of two lanes for snow-covered widths of $2.0 \mathrm{~m}$ and $2.5 \mathrm{~m}$.

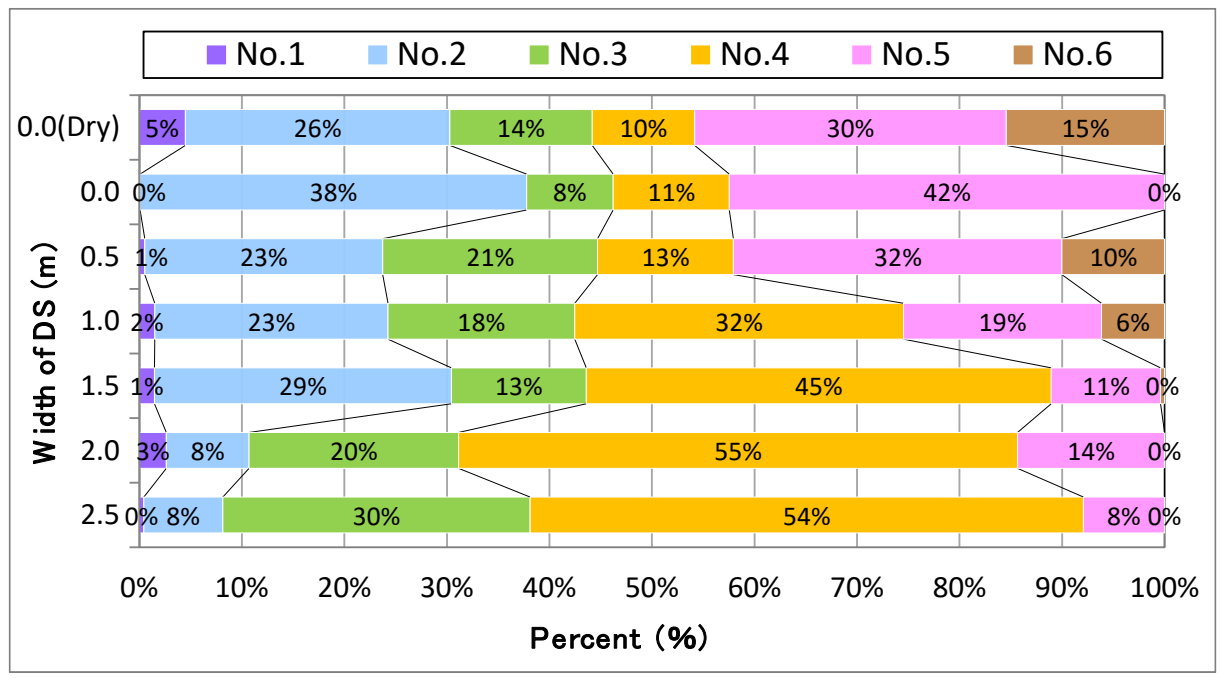

Fig. 6. Vehicle traveling position by width of deposited snow.

\subsubsection{Gap by width of deposited snow}

Data on the gap of passing vehicles by width of deposited snow were acquired and shown in percentiles, and Figure 7 was obtained.

In the autumn season on a dry road, the 50th percentile value was 3.0 seconds. The 50th percentile value was 3.8 seconds when the snow deposit width was $1.5 \mathrm{~m}$ in winter. Also, when the snow covered a width of $2.5 \mathrm{~m}$, the 50th percentile value reached 4.2 seconds.

According to HCM 2016, "the distance between the head of the preceding vehicle and the rear car is 3.0 seconds or less" is defined as follow-up. It is thought that the autumn data for the dry road obtained from this observation gave a follow-up tendency almost similar to that in HCM 2016. On the other hand, a headway distance of 3.8 to 4.2 seconds was obtained at the 50th percentile value when the width of snow was between $1.5 \mathrm{~m}$ and $2.5 \mathrm{~m}$ in winter. This data supports the tendency that "Drivers are driving with more inter-vehicle distance on roads under winter conditions." 


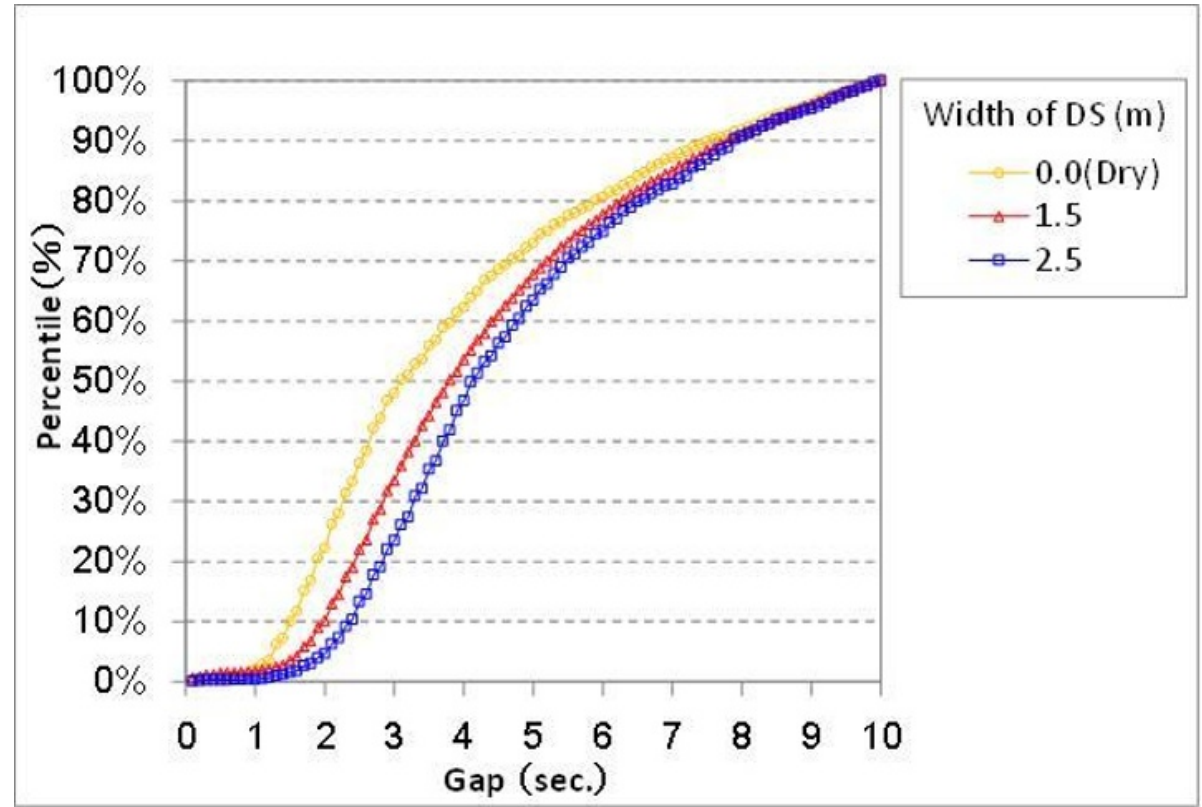

Fig. 7. Percentile of Gap by width of deposited snow.

\subsubsection{Traffic volume - speed $(Q-V)$ performance}

The data on the traffic volume (Q) per 5 minutes and the average speed (V) of passing vehicles are shown in Figure 8. In the figure, on the dry road surface in autumn, the snow deposit width of $1.5 \mathrm{~m}$ and the time of 2.5 minutes were plotted for winter.

The maximum traffic volume (Qmax) was recorded at 90 (vehicles/5min.) and the maximum speed (Vmax) was recorded at $60(\mathrm{~km} / \mathrm{h})$ during the autumn dry road conditions. The maximum traffic volume (Qmax) was 85 (vehicles/5 min.) and the maximum speed $(\mathrm{V} \max )$ was $50(\mathrm{~km} / \mathrm{h})$ for 1.5 meters of snow cover in winter. With a width of $2.5 \mathrm{~m}$ in the winter, the maximum traffic volume (Qmax) was 50 (vehicles/5 min.) and the maximum speed (Vmax) was $40(\mathrm{~km} / \mathrm{h})$. Traffic volume (Q) and speed (V) decreased as the snow deposited width increased. In particular, from $1.5 \mathrm{~m}$ in width of snow cover to $2.5 \mathrm{~m}$ in width, the maximum traffic volume (Qmax) decreased to about 60\%. This is probably because the effective lane width decreases due to snow accumulation in two lanes on one side, resulting in a phenomenon leading to operation of one lane on one side. 


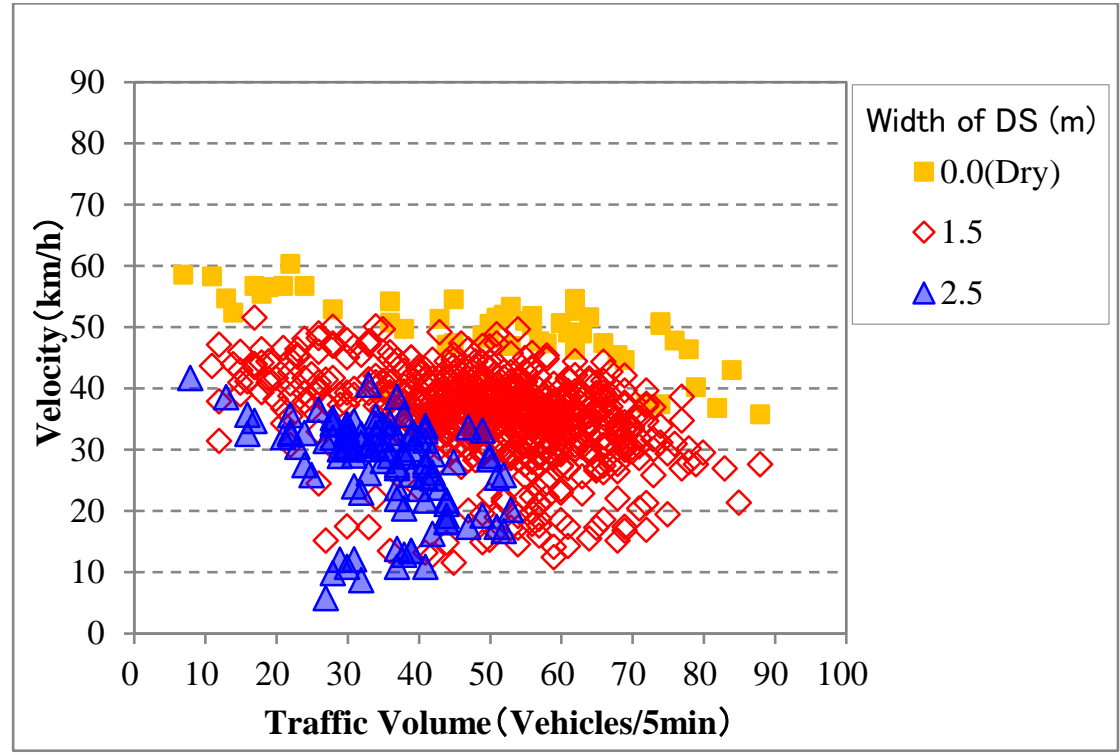

Fig. 8. Caption of the Figure 1, Below the figure.

\subsection{Measurement result in autumn}

For autumn, we measured bicycle traffic volume (units/12h) and pedestrian traffic volume (persons /12h) in the roadway / shoulder / sidewalk area as practical use of the road crosssection configuration. The measurement results are as shown in Fig. 10. The data in the table shows the average value over the 5 days measured on weekdays in November 2015.

According to Fig. 10, bicycle traffic volume of 257 units/12h and pedestrian traffic volume of 64 persons/12h were mainly observed in total in the sidewalk section. Bicycle traffic volume was also observed on the roadway and shoulder, but it was extremely small. Under the current Road Traffic Law, bicycles in principle run on the roadway. However, it was shown that the current situation of operation is a usage situation that does not conform to this principle.

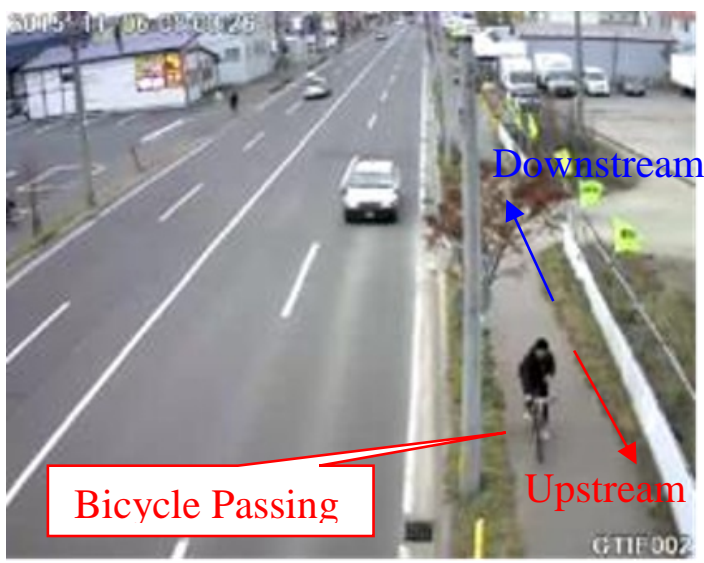

Fig. 9. Bicycle passing on sidewalk in dry autumn. 


\begin{tabular}{|c|c|c|c|c|}
\hline Traveling Position & Roadway & Shoulder & \multicolumn{2}{|c|}{ Sidewalk } \\
\hline Direction & Upstream & Upstream & Upstream & Downstream \\
\hline $\begin{array}{c}\text { Bicycle Traffic Volume } \\
\text { (Number of bicycles/12h) }\end{array}$ & 3 & 1 & 135 & 122 \\
\hline $\begin{array}{c}\text { Pedestrian Traffic Volume } \\
\text { (Persons/12h) }\end{array}$ & - & - & 37 & 27 \\
\hline
\end{tabular}

Fig. 10. Traffic Volume for Bicycle and Pedestrian (As of Nov. 2015).

\section{Conclusions}

\subsection{Decline in road traffic performance due to formation of snow cover}

By image analysis of the observation camera installed on the roadside, data was collected on the variation of the vehicle traveling position by width of snow cover. When the width of the deposited snow became $2.0 \mathrm{~m}$ or more, it was possible to grasp the actual situation that about $80 \%$ of the vehicles are moving to the center of two lanes on one side. In other words, when the width of the deposited snow falls over $2.0 \mathrm{~m}$, it is found that the operation of one lane on one side is actually used.

In addition, traffic volume - speed (QV) performance dropped significantly as the accumulation width increased. Particularly, when the snow deposit width was 2.0 m or more, the velocity distribution greatly decreased. In addition, the head spacing has also been shown to increase.

\subsection{Utilization of road cross-sectional configuration in winter and autumn}

On the other hand, in autumn, it was possible to acquire as actual observation data that it is mainly used as a space for bicycle traffic and pedestrian traffic in the sidewalk section.

Based on this actual observation, in snowy areas, construction of a road space considering compatibility between snow accumulation space in winter and bicycle passage space from spring to autumn is required.

\subsection{Proposal for redistribution of road space}

According to the explanation and operation of the current Road Structure Order, in addition to the traffic functions such as for traffic and the access to the roadside, in the sidewalk and the bicycle passage space, it is necessary to have space functions such as city formation and environmental space. Roads in this research are forced to operate with pedestrians and bicycles mixed in the present situation.

It is required to secure a bicycle passage space from spring to autumn, and secure snow cover in winter. Based on the compatibility of the bicycle passage space and snow cover space, we propose redistribution of the road space in Figure 11. 


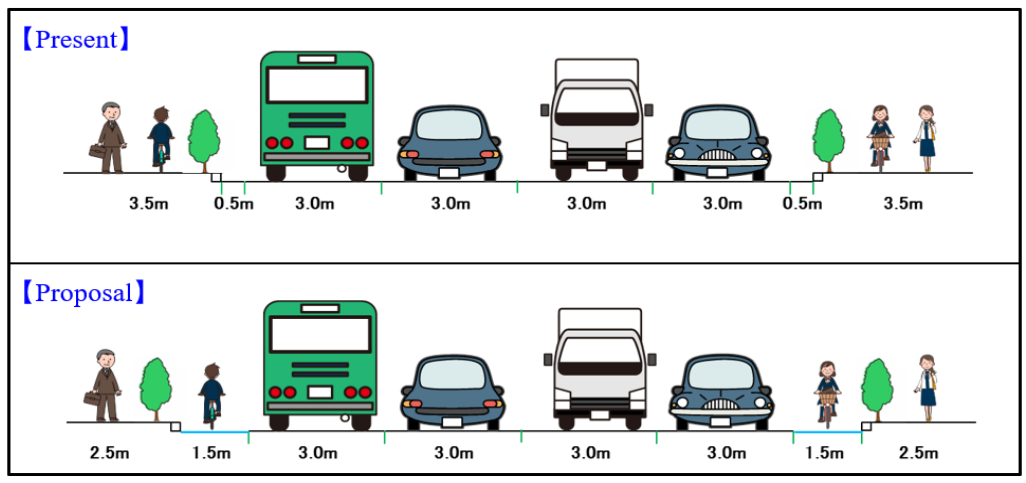

Fig. 11. Proposal for redistribution of road space.

\subsection{Efficient snow removal formulation}

In order to ensure the smoothness of winter season roads in snowy areas, appropriate snow removal plans are required. This includes daily snow removal works, Snow removal widening works, and Hauling and transportation. Further, in Japan, improvement of road structures and intelligent road surface management are required to improve snow removal efficiency.

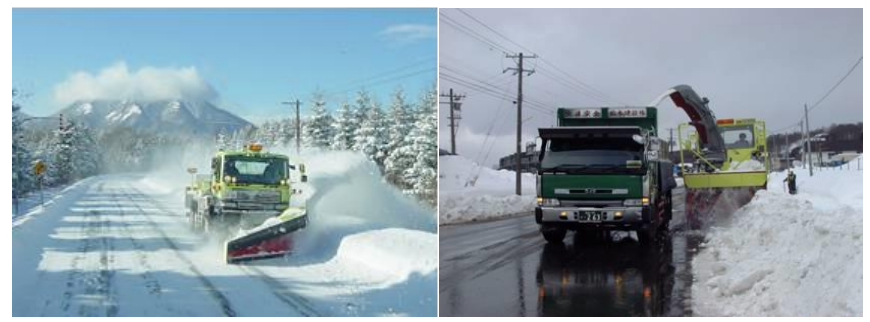

Fig. 12. Snow Removal Works (Left: Plowing, Right: Hauling).

\section{Acknowledgments}

In this research, we would like to express our gratitude to the Sapporo City government for the cooperation it provided in traffic surveying.

\section{References}

1. Japan Meteorological Agency, Data and Materials of JMA, http://www.jma.go.jp/jma/menu/menureport.html (2018)

2. Japan Road Association, Explanation and Operation of Road Structure Order 3rd Edition (1970)

3. Japan Road Ass., Explanation and Operation of Road Structure Order, 4th Ed. (1983)

4. Japan Road As., Explanation and Operation of Road Structure Order, 5th Ed. (2015)

5. E. Dogaki, K. Sato, H. Igarashi, Civil History Research 10 (1990)

6. S. Akimoto, Study on winter traffic flow observation of snowy cold district utilizing image processing device, Proc. of the 26th Japan Road Conf. (2005)

7. TRB, Highway Capacity Manual, 6th Edition (2016) 